\title{
Electroluminescence Enhancement of Polymer Light Emitting Diodes Through Surface Plasmons by Ag Nanoplates
}

\author{
T.H.T. Aziz*, M.M. Salleh, N.A. Bakar, A.A. Umar and M.Y.A. Rahman \\ Institute of Microengineering and Nanoelectronics (IMEN), Universiti Kebangsaan Malaysia, \\ 43600 Bangi, Selangor, Malaysia
}

\begin{abstract}
This paper reports a study on the surface plasmon effect of $\mathrm{Ag}$ nanoplates on electroluminescent property of polymer light emitting diodes. The diode is a single layer light emitting device made of poly [9,9-di-(2-ethylhexyl)fluorenyl-2,7-diyl (PEHF). 5 wt.\% of Ag nanoplates were incorporated into the PEHF layer. The results showed that the electroluminescence intensity of the diodes is increased by $51.85 \%$, compared with the device without the $\mathrm{Ag}$ nanoplates. The enhancement is due to the coupling process between the $\mathrm{Ag}$ surface plasmon with the emission light from the PEHF. The occurrence of the coupling process was proved firstly based on the fact that the exciton lifetime of the PEHF:Ag layer is shorter than that without $\mathrm{Ag}$, as measured by time-resolved photoluminescence spectroscopy. Secondly, the PEHF photoluminescence peak at $425 \mathrm{~nm}$ is overlaping with the surface plasmon absorption peak of $\mathrm{Ag}$ nanoplates.
\end{abstract}

DOI: 10.12693/APhysPolA.129.711

PACS/topics: 73.20.Mf

\section{Introduction}

Organic light emitting diodes (OLEDs) have attracted much scientific and commercial interest since the realization of a practical OLED, which has opened unlimited applications for future lighting technology [1-3]. In making the OLEDs a competitive light source of the current inorganic LEDs, it is necessary to improve further the efficiency of organic light-emitting diodes $[4,5]$. There are two primary considerations for the OLEDs efficiency; how much light emission is generated and how much of the generated light is extracted out. In this paper we have focused on the improvement of the light extraction. It was reported that $80 \%$ of the emitted light from OLED devices is confined in the substrate [6,7]. Various methods have been proposed to extract the emitted light, such as waveguide modes $[8,9]$, micro lens arras [10] and utilization of surface plasmons [11, 12]. The extraction of light from the OLED devices using surface plasmons is made by incorporated in the polymer emitting layer of the gold or silver nanoparticles. This paper reports the application of surface plasmon effect of silver nanoplates to enhance the luminescence brightness of the OLED devices.

\section{Materials and methods}

Ag nanoplates were synthesized using the chemical method described by Zhang et al. [13]. The poly [9,9-di(2-ethylhexyl)-fluorenyl-2,7-diyl] (PEHF) was purchased from American Dyes Source, and was used without any purification. The amount of $9 \mathrm{mg}$ of PEHF was dissolved in $1 \mathrm{ml}$ of toluene. The PEHF solution was

*corresponding author; e-mail: hasnanaziz@ukm.edu.my blended with 5 wt.\% of synthesized Ag nanoplates solution to form a nanocomposite of PEHF:Ag. Light emitting diodes with the structure of ITO/PEHF:Ag/Al were fabricated (Fig. 1). The emitting layer of PEHF:Ag

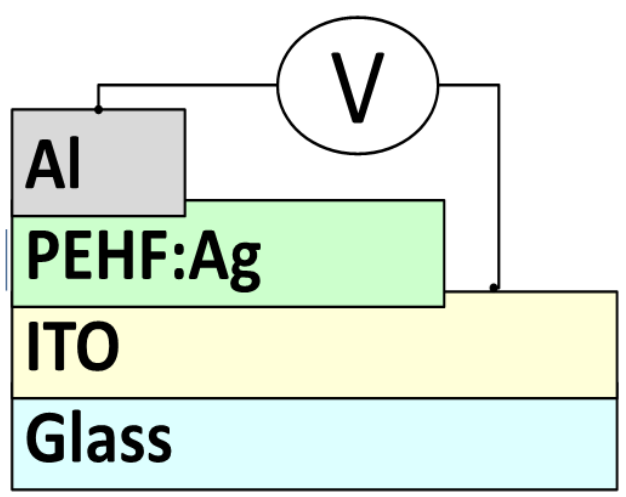

Fig. 1. Schematic structure of PEHF: Ag nanocomposite device.

nanocomposite was spin coated onto ITO at $3000 \mathrm{rpm}$ for $40 \mathrm{~s}$. The aluminum cathode of $150 \mathrm{~nm}$ thickness was deposited using a thermal evaporator. As for control device, another light emitting diodes with structure of ITO/PEHF/Al were also fabricated. The light emitting diodes were characterized by recording the currentvoltage $(I-V)$ curves using Keithley SMU 238, then the electroluminescence (EL) was measured using Ocean Optic USB2000. The optical properties of nanocomposite PEHF:Ag layer were characterized using Edinburgh Fluorescence Spectrometer FLSP920 for exciton lifetime, the LS 55 Fluorescence Spectrometer for photoluminescence and Perkin Elmer Lambda 900 UV-Vis Spectrophotometer for absorption spectrum. 


\section{Results and discussion}

Figure 2a shows the current voltage $(I-V)$ curves of the light emitting diodes with nanocomposite PEHF:Ag and of the control device. The $I-V$ curves were used to determine the turn-on $\left(V_{\text {on }}\right)$ and the operating voltages $\left(V_{\mathrm{op}}\right)$ of the devices. The $I-V$ curves for both devices have no significance differences. That means the devices have almost similar $V_{\text {on }}$ and $V_{\text {op }}$. Figure $2 \mathrm{~b}$ shows the electroluminescence spectra of both devices. The spectra of both devices showed an electroluminescence peak at $553 \mathrm{~nm}$, however the nanocomposite device has a higher electroluminescence brightness. The numerical values of turn on voltage, operating voltage, electroluminescence brighness and peak wavelength, obtained from Fig. 2 are summarized in Table I. The results indicate that by incorporating the Ag nanoplates in the light emitting layer, the electroluminesecene brightness was increased by $51.85 \%$, compared with the control device.
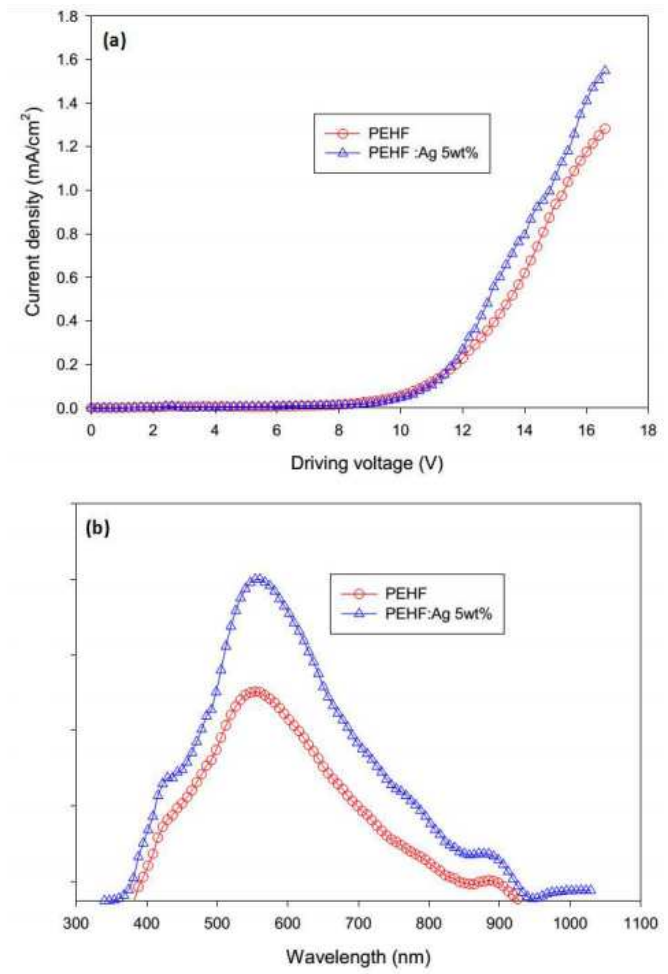

Fig. 2. (a) Current-voltage and (b) electroluminescence characteristics of fabricated devices.

We assume that the electroluminescence enhancement of the nanocomposite light emitting diodes is due to the coupling process between the Ag surface plasmons and the light emitted from the PEHF. To prove this assumption, we measured the exciton lifetime for both PEHF:Ag nanocomposite and PEHF layers. The results shown in Fig. 3a, indicate that the exciton lifetime of nanocomposite (10.692 ns) is shorter than that of the PEHF layer (11.651 ns). Xiao et al. [14] has explained that the coupling process between the surface plasmons
TABLE I

Summary of fabricated devices performance.

\begin{tabular}{c|c|c|c|c}
\hline \hline Device & $\begin{array}{c}\text { Turn } \\
\text { on } \\
\text { voltage } \\
{[\mathrm{V}]}\end{array}$ & $\begin{array}{c}\text { Operating } \\
\text { voltage } \\
{[\mathrm{V}]}\end{array}$ & $\begin{array}{c}\text { Brightness } \\
\text { [cd] }\end{array}$ & $\begin{array}{c}\text { Wavelength } \\
{[\mathrm{nm}]}\end{array}$ \\
\hline ITO/PEHF: Ag/Al & 11.0 & $11.0-17.0$ & 270 & 553 \\
ITO $/ \mathrm{PEHF} / \mathrm{Al}$ & 12.0 & $12.0-17.0$ & 140 & 553
\end{tabular}

and the emitted light occurs when the exciton lifetime is shorter, compared with that of the the emitted light of the polymer. Further criterium of coupling between the surface plasmons and the emitted light is that the absorption peak of metal nanoparticles and the photoluminescence peak of the emitting layer must nearly overlap $[14,15]$. As shown in Fig. 3b the PEHF photoluminescence peak at $425 \mathrm{~nm}$ is overlapping with the surface plasmon absorption peak of Ag nanoplates.
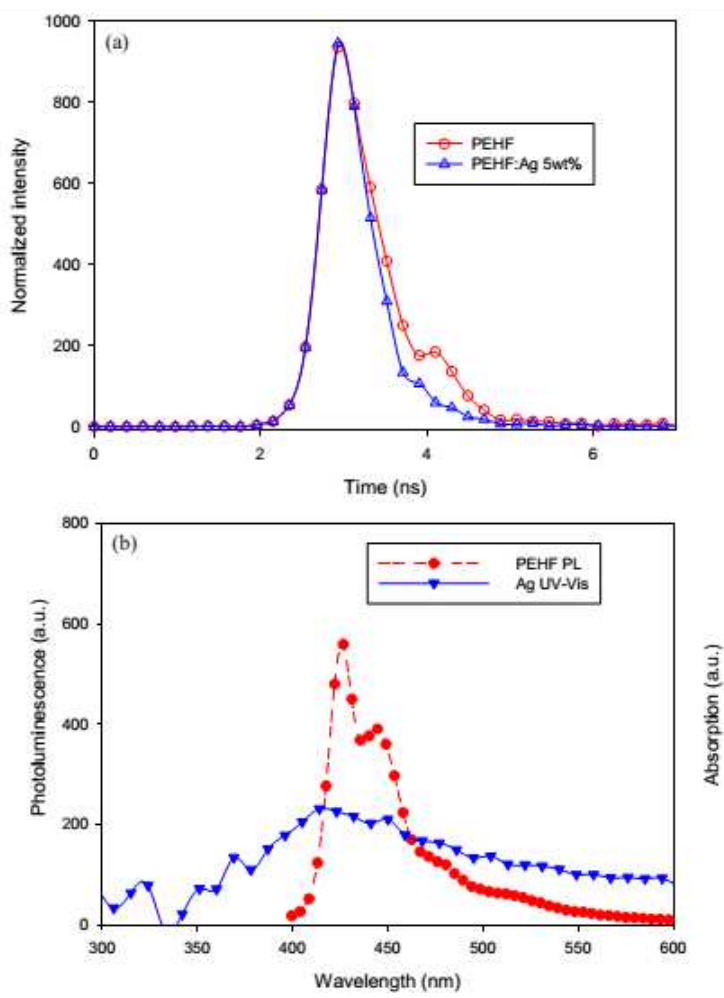

Fig. 3. (a) Time-resolved spectra for exciton lifetime. (b) Spectra for Ag nanoplate absorption and PEHF photoluminescence.

\section{Conclusion}

This study has demonstrated that the incorporation of $\mathrm{Ag}$ nanoplates in the emitting layer of the light emitting diodes is able to enhance the electroluminescence brightness of the devices. The enhancement is due to the coupling process between the Ag surface plasmons with the emission light from the PEHF polymer. 


\section{Acknowledgments}

This work was supported by Universiti Kebangsaan Malaysia under research grant AP-2012-015.

\section{References}

[1] M.-K. Wei, C.W. Lin, C.C. Yang, Y.W. Kiang, J.H. Lee, H.Y. Lin, Int. J. Mol. Sci. 11, 1527 (2010).

[2] A. Kumar, R. Srivastava, D.S. Mehta, M.N. Kamalasanan, Org. Electron. 13, 1750 (2012).

[3] J. Liang, L. Li, X. Niu, Z. Yu, Q. Pei, Nat. Photonics. 7, 817 (2013).

[4] X. Gu, T. Qiu, W. Zhang, P.K. Chu, Nanoscale Res. Lett. 6, 199 (2011).

[5] W.L. Barnes, Nature 3, 588 (2004).

[6] J.B. Kim, J.H. Lee, C.K. Moon, S.Y. Kim, J.J. Kim, Adv. Mater. 25, 3571 (2013).

[7] J. Vuckovic, M. Loncar, A. Scherer, IEEE J. Quantum Electron. 36, 1131 (2000).
[8] K. Okamoto, I. Niki, A. Shvartser, Y. Narukawa, T. Mukai, A. Scherer, Nat. Mater. 3, 601 (2004).

[9] X. Wu, M.H. Chowdhury, C.D. Geddes, K. Aslan, R. Domszy, J.R. Lakowicz, A.J.-M. Yang, Thin Solid Films 516, 1977 (2008).

[10] R. Singh, K.N. Narayanan Unni, A. Solanki, Opt. Mater. (Amst.) 34, 716 (2012).

[11] Z. Wang, Z. Chen, L. Xiao, Q. Gong, Org. Electron. 10, 341 (2009)

[12] D.M. Koller, A. Hohenau, H. Ditlbacher, N. Galler, F. Reil, F.R. Aussenegg, A. Leitner, E.J.W. List, J.R. Krenn, Nat. Photonics 2, 684 (2008).

[13] Q. Zhang, N. Li, J. Goebl, Z. Lu, Y. Yin, J. Am. Chem. Soc. 133, 18931 (2011).

[14] Y. Xiao, J.P. Yang, P.P. Cheng, J.J. Zhu, Z.Q. Xu, Y.H. Deng, S.T. Lee, Y.Q. Li, J.X. Tang, Appl. Phys. Lett. 100, 013308 (2012).

[15] K. Okamoto, I. Niki, A. Scherer, Y. Narukawa, T. Mukai, Y. Kawakami, Appl. Phys. Lett. 87, 071102 (2005). 